A Reprint from

HISTORY of PHILOSOPHY

Volume XV / January, 1977 / Number 1 


\title{
Clarke, Collins and Compounds
}

\author{
ROBIN ATTFIELD
}

CAN ROOM BE FOUND in between the matter and void of a Newtonian universe for an immaterial and immortal soul? Can followers of Locke with his agnosticism about the nature of substances claim to know that some of them are immaterial? Samuel Clarke, well versed in Locke's thought and a defender both of Newtonian science and Christian orthodoxy, believed he could do both and attempted to prove his case by means of some hard-boiled reductionism. Anthony Collins, a deist whose only lapse from materialism concerned God himself, rejected Clarke's argument. In this paper I discuss their controversy' in order to bring out the state of debate about material systems and consciousness among men influenced by Locke and Newton in the early eighteenth century, and I also assess Clarke's reductionist premise, as he himself frequently invites the "impartial reader" to do.

I. The controversialists must first be introduced. Samuel Clarke (1675-1729) was one of the foremost defenders of Newtonian physics in his day. In 1695 he produced a Latin translation of Rohault, the Cartesian textbook, with annotations which brought out the superiority of Newton's system; and in 1706 he translated Newton's Optics. ${ }^{2}$ Later he was to be Newton's spokesman in an extended controversy with Leibniz. ${ }^{3}$ By the time of his controversy with Collins (1706-1708) he was also well known for his Boyle Lectures of 1704 and 1705, in which he defended natural theology and an intuitionist theory of ethics; and his ecclesiastical appointments by then included the honor of being chaplain in ordinary to Queen Anne.' Clarke, who was himself later to be arraigned before Convocation for alleged Arianism, at one point implied that Collins the deist "believed too little." Collins's final words in the controversy comprise the following judicious reply: "I shall not make that Return which such an Insinuation does suggest and would justify, but instead thereof will give him on this occasion a Testimony in his favour, before I finally take my leave of him; That I verily think he neither believes too little nor too much; but that he is perfectly and exactly Orthodox and in all likelihood will continue so." ${ }^{5}$ Some have taken Clarke as the model for Demea, the unbending a priorist of Hume's Dialogues Concerning Natural Religion.

Anthony Collins, the other disputant, was a year Clarke's junior, and was to die the same year as Clarke. His reputation as a deist is based largely on writings later than

\footnotetext{
'To be found in Samuel Clarke, A Letter to Dodwell; Wherein all the Arguments in his Epistolary Discourse against the Immortality of the Soul are particularly answered. . . . Together with a Defence of an Argument made use of in the above-mentioned Letter to Mr. Dodwell, to prove the Immateriality and Natural Immortality of the Soul. In Four Letters to the Author of "Some Remarks, Etc. . . ." 6th ed. (London, 1731).

Dictionary of National Biography, s.v. "Clarke, Samuel."

See The Leibniz-Clarke Correspondence, ed. H. G. Alexander (Manchester University Press, 1956); on Clarke's relation to Newton, see p. xii.

$D N B$, s.v. "Samuel Clarke."

Letter to Dodwell, p. 390.
} 
their controversy: his only published work up to that time was his An Essay Concerning the Use of Reason in Propositions, the Evidence whereof depends upon Human Testimony (1707), and this was anonymous (yet not enough to prevent Clarke twitting him on apparent disagreements with its author, whom Collins was likely to hold in respect9. It involved an attack on the Lockeian view that there are truths above reason which we should accept on authority. Nevertheless Collins had established close personal ties with Locke in the last two years of his life, and he may be seen in the correspondence with Clarke as developing Locke's own suggestion that possibly thinking is a power of systems of matter, and that the soul is material.'

In the passage concerned, Locke alludes to the difficulties both for and against the soul's "materiality." It is hard, he says, to reconcile sensation and extended matter (maybe because matter was assumed to be inert); yet it is hard to ascribe existence to anything lacking extension. Locke and Clarke alike seem to have endorsed Hobbes's view that what is nowhere is nothing: hence Clarke's belief in God's spatial omnipresence' and his reluctance to conceive the soul as unextended. ${ }^{9}$ Clarke's tacit acceptance of the extendedness of souls exposed him to Collins's most effective criticism, as we shall see.

Locke's influence on Clarke was perhaps greatest in the matter of his distinction among primary qualities, secondary qualities and powers. ${ }^{\circ}$ Collins also accepts this threefold division of qualities, though his interpretation is not wholly at one with Clarke's. They nevertheless agreed that the real qualities of material objects are qualities such as their shape, solidity, extension and motion, and that other qualities are really effects of primary qualities either upon the beholder (as in the cases of "Heat, Colour, Smell, Taste, Sound and the like"") or upon some other substance again. Indeed Clarke held that the so-called powers of things (such as magnetism) are mere names for the motion either of the substances concerned or some other.'2 Collins in fact resisted the exhaustiveness of Clarke's "disjunction" of qualities (as either primary qualities, secondary qualities or mere nominal powers), holding that a power like that of the eye to see is a counterexample; but he was prepared to accept that this power was a mode of the motion of the parts of the eye."

Among the powers treated by Clarke as "merely abstract Names" was Gravitation. ${ }^{\text {" }}$ This power "is not a Quality inhering in Matter, or that can possibly result from any Texture or Composition of it; but only an Effect of the continual and regular Operation of some other Being upon it; by which the Parts are all made to tend one towards another." The Being intended by Clarke is no second material object to

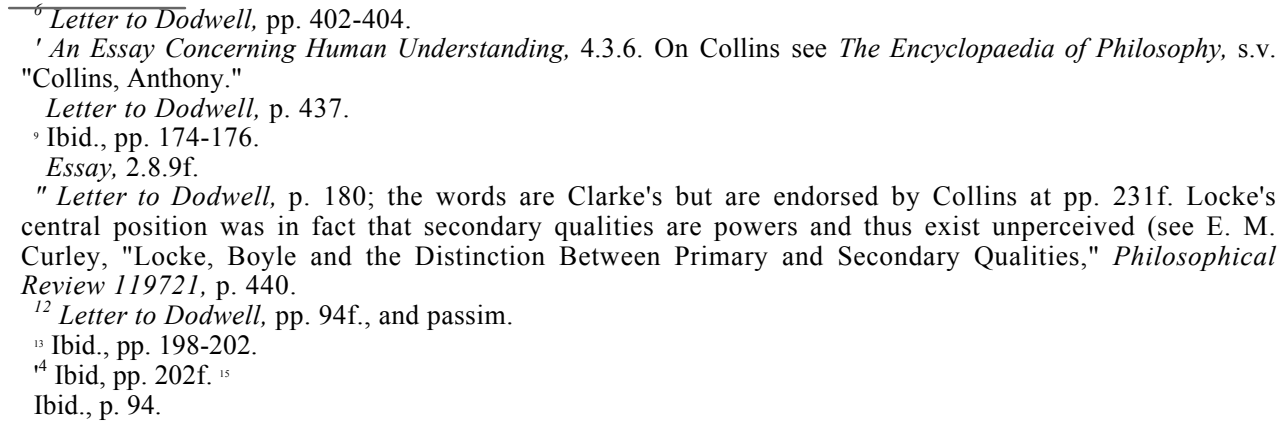


which the first is attracted, for all material objects are inert. Besides, no material object can be responsible for the internal cohesion of the parts of any other material object. Given his commitment to the inertness of matter, Clarke in fact explains the phenomenon of gravity by continual divine activity. This view was almost certainly shared for periods of his life by Newton," despite Newton's official view that the cause of gravity is unknown. Collins was inclined to the opposed view that gravity is a natural power of matter, originally placed in it by God, ${ }^{7}$ only to be chastised by Clarke for holding that gravity, which was merely an abstraction, could impel a body such as a stone to fall." But as Koyre relates, Newton's close collaborator, Roger Cotes, was later to surmise, cogently but falsely, that the view that gravity is a property of matter was Newton's own. ${ }^{9}$ So Collins's view was not mere opportunism. Collins in fact took a more inclusive view of primary qualities and a more realistic view of powers than Clarke, and he was willing to ascribe active capacities to matter.

The controversy between Clarke and Collins was sparked off when Clarke wrote to Henry Dodwell the elder in 1706 criticizing as false and inimical to religion his view that the soul is not naturally immortal. Clarke produced an intended demonstration of the soul's immateriality and natural immortality, but at this point Collins began confronting him with a barrage of replies. The controversy continued into 1708, and the correspondence concerned ran to over 400 pages and six editions; it was still being reprinted after both authors were dead. It was discussed in numerous pamphlets ${ }^{2 \circ}$ not only in Britain but also in Amsterdam, ${ }^{21}$ and Clarke's replies were still being commended by Richard Price in the 1770s. ${ }^{22}$ The tone of these letters is cool, but there are frequent professions of deference to the rules of debate, and the correspondence is unusually free of rancor for its day.

The strictures of Hume on both sides in the dispute between materialists and immaterialists have persuaded many of its futility. Fundamentally the issue between Collins and Clarke was the nature of the substance to which consciousness belongs, and Hume may have had them in mind when he contended that as there may be no substance which underlies consciousness, disputes about whether it is material or not are idle $2^{3}$ Hume, however, was able to maintain this view only as a result of holding that each perception and thought may be a distinct existence, only contingently related to the perceiver or thinker to whom it occurs, and presumably able to exist independently of any subject whatever. If this is true, then there need be no substance to which thought belongs. But it cannot be true, for perceivings and thinkings cannot be identified or individuated unless something whose thinkings they are can be picked out. Necessarily thoughts are somebody's thoughts; they cannot exist unattached. Hume must be wrong. As we have seen, interest in Clarke's debate with

\footnotetext{
"See Alexandre Koyre, Newtonian Studies (London, 1965), pp. 108f.

Letter to Dodwell, p. 123.

" Ibid., p. 169.

19 In "Attraction, Newton and Cotes," Newtonian Studies, pp. 273-282.

" See British Museum Catalogue, s.v. "Collins, Anthony."

${ }^{2}$ Cf. Jean Le Clerc, An Abstract and Judgment of Dr. Clarke's Polemical or Controversial Writings against I The Atheists, II The Deist, III His Controversy with Mr. Dodwell and Mr. Collins, etc. (Amsterdam, 1713).

$\mathrm{n}$ In A Free Discussion of the Doctrines of Materialism and Philosophical Necessity, in a correspondence between Dr. Price and Dr. Priestley, Etc. (London, 1778).

23 Treatise of Human Nature, bk. 1, pt. 4, secs. 5, 6.
} 
Collins survived Hume's strictures; and in any case those strictures failed to show it to lack philosophical importance.

The philosophical importance of the debate emerges more clearly when Clarke's argument against the materiality of the subject of thought is considered. Clarke's crucial premise is his reductionist thesis (to be considered in Section II), namely, that the qualities of a system or compound substance are the sum or resultant of qualities of the same sort in the components. ${ }^{24}$ Suitably interpreted, this thesis implies the reducibility of language about societies to talk of individuals, and of biology to physics: indeed it might also seem to imply the reducibility of psychological language to neurology. But this latter is the exact contradictory of Clarke's conclusion. We should therefore attend to its-place in his argument.

Clarke's argument involves setting his reductionist thesis alongside the generally accepted proposition that whatever is material is divisible either by ordinary physical means or at least (as no doubt Clarke held about atoms) by the power of God. Thus all material objects are composite. If, then, it is granted that the qualities of compounds are the sum or resultant of similar qualities in the compounds, then were the soul material, consciousness would be the sum or resultant of qualities closely resembling consciousness in its material components. But this is false: for neither does each thinker consist of a colony of little thinkers, nor is there any quality at all like consciousness which might characterize the parts of the brain and of which consciousness could at all plausibly be the resultant. Indeed, the unity of consciousness and the facts of memory and self-awareness make it highly implausible that it is the tying together of any bundle or in any way a resultant quality at all. But if it is not, then the substance which thinks cannot be a material one. Being irreducible into qualities of the parts of what it belongs to, consciousness cannot reside in anything composite or divisible. Hence the soul must be immaterial.

Clarke acknowledges the Platonic origins of arguments for the immateriality of the soul when he first presents this reasoning to Dodwell." (Theologians nowadays agree that its conclusion is no part of New Testament thought.) The view that the soul is noncomposite and naturally indestructible is expressed by Socrates in the Phaedo $;^{26}$ while a premise similar to Clarke's is implicit in Socrates' reply to Simmias's view there that the soul is "a harmony or a composite thing of some sort. ${ }^{27}$ Socrates in fact persuades Simmias that a composite thing cannot be "in any other state than that in which the elements are of which it is composed." Whether or not Clarke recalled this passage as the source of his reductionist premise, Plato's use of it shows it to have been employed by immaterialists long before it fell into the hands of methodological individualists or other modern reductionists. Similarly Collins, in accepting it in a weak form only, was treading the path of many a wary materialist before him from Epicurus onwards: holding as he did that consciousness is a mode of the motion of material particles," he found it an embarrassment to have quoted to him the words of an uncompromising materialist, Hobbes, to the effect that "no Result of Motion can ever be any thing else but mere Motion still.""

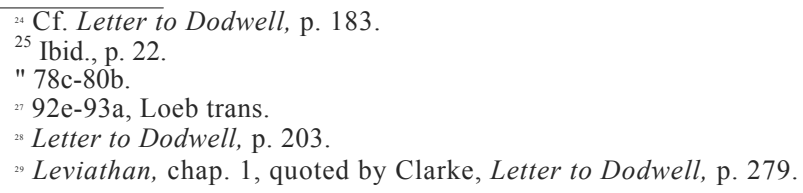


How then was Collins to reply? For if primary qualities alone are considered, the reductionist thesis appears hard to flaw. Thus the weight of a horse and cart is precisely the sum of the weights of the horse, the wheels, the bodywork, etc., and the height of a wall above the ground is indeed the sum of the sizes of those of its component bricks and layers of cement which are themselves above ground. On the other hand, the term "sum" is not always appropriate, for the parts may overlap, like the parts of a pneumatic drill with its drilling limb retracted. Indeed, in order to deduce the qualities of a composite object from those of its parts we must be told how the components are mutually related. Such an account will henceforth be termed a "proposition of composition." (Such a proposition, it should be noted, need not include either the name of the whole, or the terms "parts" or "components," for the parts of a genuinely composite object can be identified otherwise than as parts of that object.) Collins could then have protested over Clarke's talk of the sum of the qualities of the components, but he would still have needed a reply to the view that qualities of compounds are the resultant of components' qualities.

Collins's actual line of attack, however, concerned the phrase "of the same sort," and he attempted to distinguish two senses of this phrase, on the first of which Clarke's premise was false and on the second of which it was true but harmless to his materialism.

I distinguish between Numerical Powers and Generical Powers. By Numerical Powers I understand such Powers as Motions and figures of the same Species. The Power of the Eye to contribute towards seeing is a Species of Motion, and the Roundness of a Body is a Species of Figure. By Generical Powers I understand all the several Species of Numerical Powers; as Motion signifies all the various Species of Motion and Figure all the various Species of Figure.

Now if the Reader will be pleased to apply the foregoing Distinction, he may see that the whole of the Objection is founded on an Equivoque of the Terms, Powers of the same kind: for if Powers of the same kind be understood generically, then I do agree that the known Powers of Matter are nothing else but the Sums or [sic] Powers of the same kind; that is, the Figure and Motion of a Body consist of the figures and Motions of the Parts. But if the Terms Powers of the same kind be taken numerically, (that is, as Powers really exist) then there are Powers inhering in Systems of Matter that are not the Sums of Powers of the same kind: As the Roundness of a Body is not the Sum of the Roundness of the Parts: nor the Power of a musical Instrument to cause an harmonious Sound, the Sum of Powers of the same kind in the Parts singly considered. ${ }^{80}$

Collins proceeds to maintain that consciousness is a numerical power, while motion is a generical one. Thus if consciousness is a mode of motion, the consciousness of a material system need not be the resultant of the consciousness of its parts but only of different sorts of motion in its parts. Collins thus disputes both the reducibility of consciousness and the relevance of the reductionist thesis. $\mathrm{He}$ is unwilling to treat consciousness as either a secondary quality or an abstraction but wants to include it among the primary qualities of some material systems.

But, as Clarke replies, Collins's distinction will hardly do." Whether two objects are said to be "numerically" or "generically" of the same sort will depend on how determinate the quality is which one looks for before granting numerical sameness. Thus if circularity is looked for, a circle and its segments are not of the same

\footnotetext{
"Letter to Dodwell, pp. $202 \mathrm{ff}$.
}

" Ibid., p. 249. 
numerical sort; but Clarke's own argument does not require that in this construction of "same sort" they should be. It is enough for him that both a circle and its parts

conform to the same formula relative to the same co-ordinates; and granted this, the parts are relevantly of the same sort as the circle, whether deemed numerically of the same sort or not.

The harmony of a musical instrument is "it self, in the Mind that perceives it, nothing but Sound; and, in the Organs of Sensation, nothing but a Motion of Parts," so it "cannot be the Result or Composition of any other Powers, but what are themselves singly of the same Kind in the several subjects respectively; namely, in the Mind that perceives them, Sounds likewise; and, in the Instrument it self, and in the Air, and in the Organs of Sensation, Motion of the Parts." ${ }^{32}$ The source of this reply may in part be Plato (see above); granted widespread acceptance of the Lockeian distinction between primary and secondary qualities, it would have been taken as peculiarly convincing.

While upholding his reductionist thesis without qualifying it, Clarke also insisted on its relevance to the argument about consciousness. For with what plausibility could it be alleged that consciousness was of the same sort as motion? If it is the resultant of qualities "void of thought" ${ }^{33}$ it must consist of qualities not only numerically but also generically different from itself. If consciousness were a resultant quality, what it resulted from must surely at least be in the same category as itself.

Thus Collins's admission that qualities of compounds must be of the same generical sort as the qualities of components was made to appear to the readers like an admission of defeat. For while not disputing the divisibility of matter and not succeeding in making plausible the case for the reducibility of consciousness to agreed primary qualities, he granted that if consciousness is a quality of something composite (which he admitted matter to be), it is the resultant of qualities of the same generical sort in the components. However, since he had failed to make the consequent of this conditional appear other than implausible, the same judgment appeared called for of its antecedent, i.e., that consciousness is a quality of anything composite.

Collins did not, of course, grant this; but his case looks thin indeed, granted his and Clarke's agreements and shared assumptions. His consolation, however, consisted in a to quoque. For if (as Clarke evidently believed) the soul is extended, it too must be divisible, at least by the power of God, and thus it too must be composite. And if, as Clarke held, compositeness excludes consciousness, the soul cannot be conscious.

On the other hand, if it is conscious because naturally indivisible, the same could apply to matter: God could have so made matter that it was naturally indivisible and thus able to bear consciousness. ${ }^{34}$ Clarke's reply, that what is extended may, like the parts of space, be indiscerptible (unable to be torn apart) is little help to him.

Collins may here have lighted upon an important point which could be brought out in other ways. For while Clarke appears to grant that composite objects are real and the proper subjects of genuine qualities, his belief that these qualities are really the qualities of components related in a certain way commits him to the view that only

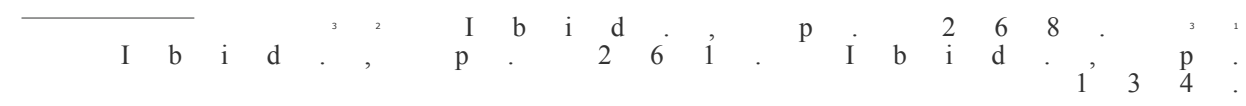


noncomposite things are ultimately real and that compounds are merely aggregates. Thus at page 96 Clarke shows that he regards only indivisibles as individuals: "Supposing any Particle of Matter could be truly an Individual that is, an Indivisible or Indiscerptible Being. . . ." But granted further the infinite divisibility of matter under God" the implication is that no physical object of any finite size is properly speaking an individual, a view of his later adversary Leibniz which he himself would have been reluctant to endorse.

If this conclusion is to be resisted, and macroscopic objects are to be allowed to exist in their own right with genuine qualities of their own, then Clarke's reductionist thesis needs looking at again, as in the section following. Perhaps Collins was correct in surmising that, after all, some material objects may constitute "wholes" with irreducible qualities of their own.

It might appear that at least some of Clarke's difficulties could be avoided by denying extension to the soul. Probably Clarke would have replied that what exists must be somewhere, and also that what is unextended can scarcely cause movement in what is extended, but that the soul, in setting the body in motion, does just this. $\mathrm{He}$ would have required the soul to be extended so as to explain the interaction of soul and body. This seems to leave his argument for its immateriality in a sorry plight: but he would insist that it is enough to maintain that the soul despite its extension is indivisible and that hence it is quite unlike matter.

Nor was Collins in a good position to object, given his qualified acceptance of Clarke's reductionist thesis. But short of a revision of the view that all primary qualities are measurable ones, that thesis is at least hard (though perhaps not impossible) to resist. For the measurable qualities of compounds are all too likely to be deducible from the measurable qualities of components. ${ }^{36}$ Thus, among those who accepted Locke's theory of primary qualities, Clarke's argument was likely to command assent. Corpuscularianism thus seemed directly to support the view that the subject of thought is immaterial. Even people like Collins who rejected the orthodox Newtonian view that matter is inert could resist immaterialism about the soul only by contending that it is made up of quasi-conscious particles; and this theory, as we have seen, had troubles of its own.

II.

Must we really accept Clarke's reductionist thesis? To consider it more closely, a way must be found of spelling out his term "result." For Clarke clearly does not have in mind causal resultancy, as when a broken nose results from a rugby scrum. His discussion of circles and their segments suggests that his thesis is a logical one, for when in geometry one quality results from another, it is meant that, given certain definitions and axioms, the correct predicability of the one quality follows from that of the other.

By "resultancy" then, I suggest that Clarke has in mind a thesis about what brings about in logic the qualities of compounds. In more modern terms his thesis may be construed as follows: "propositions in which qualities are predicated of compound

\footnotetext{
"Ibid., pp. $97 \mathrm{f}$

" As argued by Peter Alexander, in•"Curley on Locke and Boyle" (Philosophical Review [1974j, pp. 229237), the underlying belief of both Boyle and Locke about macroscopic objects was that their powers are deducible solely from the qualities of their corpuscles and their corpuscles' organization.
} 
objects are deducible from propositions in which qualities of the same sort are predicated of their components, together with some proposition of composition." The latter element is indispensable, for "the function $\mathrm{AB}$ is circular" is in no way equivalent to "each of the functions $\mathrm{AC}$ and $\mathrm{CB}$ follows a path equidistant from some one point." It is necessary also to say how the functions are mutually situated. But granted the inclusion of a suitable proposition of composition Clarke's case holds good over circles.

The inclusion of a proposition of composition in this thesis forestalls what would otherwise be a crucial objection. For there is at least one proposition true of every compound in which what would otherwise be a logically nonresultant property is predicated of it, namely, the proposition that it is composite. But if a proposition of composition is included, the compositeness of the resultant compound may be derived and the thesis survives the objection. Indeed, at least over the examples of the weight of a horse and cart and of a wall's height, Clarke's thesis does seem to work.

Nevertheless, the implications of Clarke's thesis are paradoxical. We should not wish to say that propositions about a horse's running or a horse's life boil down simply to propositions about the functioning of (its) members, so long as they are related in a certain way. It is true not that the members, when suitably placed, run or live but that the horse runs and lives. Again it is implausible that a clock's showing the time consists in its parts showing the time, however well we describe their relations, unless we specify that they are parts of a clock, which we cannot say if we are to avoid circularity.

Opponents of Clarke might then be well advised to concentrate on features of compound objects like powers of functional objects. Functional objects like clocks are typically composite and in any case divisible: yet in a sense there is a limit to their divisibility. Would something which lacked the potential when wound up to show the time count as a clock? Certainly there are clocks which no longer work, but they can only be the exceptions. It is thus no extravagance to introduce the new term "clock" such that whatever lacks the potential to show the time (even when wound up) is no "clock." Smashed, non-functional clocks will not in this sense be "clocks."

"Clocks," then, are classified as such not in virtue of components and composition alone but also in virtue of a potential for a characteristic function. (Indeed "clocks" are not so very unlike clocks in the ordinary sense which - if artifacts - must at any rate have been designed with a view to this function.) But of "clocks" as defined above it is clearly a contingent fact that springs, cogwheels and hands do when arranged in a certain way constitute a "clock," for there is no contradiction in an object so composed not being able to show the time, however primed. Thus the aggregate of clock-components however clockishly arranged may or may not be a "clock."

The property of having a potential, when wound up, for showing the time turns out therefore to be a logically nonresultant quality of something (a "clock") identical with a compound object. But it has not been shown to be a logically nonresultant quality of a compound object as such: as far as the argument goes so far, none of the qualities of ordinary clocks need be logically nonresultant. And ordinary clocks are more plausibly simply assemblages of parts• unlike "clocks," after all, they retain their identity when they will no longer go.

"An example cited by Collins at p. 115, dealt with by Clarke at p. 156. 
Nevertheless, ordinary manufactured clocks too have at least one logically non-resultant property - that of being designed with a view to being able to show the time

when wound up - for if there is no contradiction in objects with the parts and structure of clocks lacking the power to show the time, there is no contradiction either in such objects not being designed with a view to having this power. The property of being designed to this end is indeed both essential to (manufactured) clocks and logically nonresultant from the qualities and arrangement of the components. In the same way all artifacts have at least one logically nonresultant property, though all are divisible and most are composite.

Nor need attention be confined to functional objects. In the case of living organisms such as horses it is of their essence under their description as horses to live and, at least typically, to be able to run, while under another description the organism is a material system. Yet as there is no contradiction in such a system lacking life and active powers, these qualities are logically nonresultant from the qualities of the parts however aptly arranged.

In general where composite objects, organisms and collectives are classified and identified not by their components and their components' collocation but in some other manner, then their essential qualities will be logically nonresultant- even if, had the qualities of the components been different, the qualities of the compounds and indeed the compounds themselves would in fact have been caused not to exist.

It seems, after all, that Clarke's reductionist thesis is at most only plausible in general if construed as a contingent one, which might assist in explaining how systems come to have their distinctive qualities, but which does not tell us what talk about those qualities really means or boils down to. And if so, we are not obliged to deny individuality to systems, organisms and collectives: given suitable criteria of identity and individuation, these fall into quite proper, self-respecting sorts. Indeed, we often need to be able to pick out composite entities before we can pick out components: we can recognize clock-hands only if we can recognize clocks.

But not even as a contingent thesis is Clarke's reductionism really plausible, for the powers of organisms like horses are not even explainable by powers of the same sorts in members or parts. The power of a horse to run cannot be explained by the neurolo-

gist or physiologist by powers to run in the nerves or muscles. Clarke can maintain his case only by representing powers as either motions (which is false), effects of motions (which is just a way of restating the problem) or functions. Thus Clarke's thesis can be maintained only if the powers of systems and organisms are declared not to exist. But if this is done, Clarke must also deny the existence of those sorts of things to which powers are essential. But these include all living beings and all organized human groups.

Can Clarke's thesis be rehabilitated? The way to rehabilitate it is to stipulate that organisms, systems and collectives are non-composite and as such qualify for the ascription of logically nonresultant qualities, while maintaining that, nevertheless, whenever the same things can be regarded as simply aggregates of parts, their qualities are deducible from the qualities and arrangement of the parts. Thus a great many qualities will be admitted to the class of logically nonresultant ones, including some (like the power to show the time) which Collins would have wished to admit, plus others like the melodiousness of a symphony, the meaning of a sentence, the colorfulness of a scene and the sense of a meeting - while qualities of composites like weights and heights remain logically resultant. And since all (but not only) 
logically nonresultant qualities are ex hypothesi primary qualities the Lockeian distinction between primary qualities and others would rapidly vanish.

But this defense of Clarke's premise undermines his argument for the immateriality of the soul. For even if it is granted to Clarke that consciousness is a logically nonresultant quality (perhaps his strongest point), there is no longer any need to postulate any immaterial substance for it to be predicated of. For among the newly welcomed sorts of individuals are humans and animals, and even though for some purposes they can be regarded as aggregates of parts (e.g., when being measured), they must for other purposes be regarded as organisms of a logically irreducible sort, as which alone they live and move. But if life and movement can be ascribed to them, there is no reason why consciousness cannot be also.

It does not follow, of course, that Collins's materialism is vindicated. Collins writes as if that which thinks were a material aggregate. But if, as Clarke seems correctly to have held, the qualities of aggregates are deducible from qualities of the same sort in the parts together with the arrangement of those parts, Collins's position about thought will be extremely difficult to uphold. There is no contradiction in a material aggregate with human parts arranged in the proper order being unable to think; and being able to think is as essential to a race of humans as is physical shape ${ }^{38}$ Consciousness must be regarded, then, as an irreducible quality not, as Collins held, of the brain, ${ }^{39}$ but of an individual animal or an individual human.

University College, Cardiff Wales

${ }^{38}$ See my "On Being Human," Inquiry, 17 (1974).

${ }^{39}$ Letter to Dodwell, p. 211. 